\title{
Alpha toxin specific PCR for detection of toxigenic strains of Clostridium perfringens in Poultry
}

\author{
Malmarugan Shanmugasamy, Johnson Rajeswar \\ Veterinary College and Research Institute, \\ Tamilnadu University of Veterinary and Animal Sciences, Namakkal-637 002, Tamilnadu, India \\ Corresponding author: Malmarugan Shanmugasamy, email:micromals@rediffmail.com \\ Received: 19-12-2011, Accepted: 22-01-2012, Published Online: 10-03-2012 \\ doi: $10.5455 /$ vetworld.2012.365-368
}

\begin{abstract}
Aim : Isolation of Clostridium perfringens from necrotic enteritis cases in poultry and confirmation by alpha toxin specific PCR Materials and methods: Robertson cooked meat medium with Brain Heart Infusion broth was used for isolation of $C$. perfringens from intestinal contents of necrotic enteritis suspected birds. Positive cultures from perfringens agar were further confirmed by biochemical tests and subjected to alpha toxin specific PCR.

Results and Discussion: Twenty Clostridium perfringens isolates were isolated from intestinal contents of thirty five NE suspected birds. Out of the twenty isolates, fourteen were isolated from commercial broilers of 2 to 6 wk of age and six from commercial layers of 9 to $15 \mathrm{wk}$ of age. Frequency of isolation of $C$. perfringens was more with Robertson cooked meat medium with BHI broth than thioglycollate broth alone. When positive cultures were streaked on to clostridial agar appreciable luxuriant growths were obtained and the selective streaking of these colonies on perfringens agar with supplements revealed rough and black colonies with sulphate reduction. The isolates produced rough and black colonies with sulphate reduction on perfringens agar, double zone haemolysis on sheep blood agar, stormy clot fermentation on milk medium and opalescence on egg yolk medium. The isolates were found negative for oxidase, catalase, liquefied gelatin, fermented glucose, maltose, lactose and sucrose except mannitol. All the fourteen isolates obtained from commercial broilers proved the alpha toxin producing strains of $C$. perfringens when they were subjected to alpha toxin specific PCR.

Conclusion : This study revealed alpha toxin specific PCR is highly useful for detection of toxigenic strains of Clostridium perfringens in poultry

Key words: Alpha toxin, Clostridium perfringens, Necrotic enteritis, PCR, Poultry
\end{abstract}

\section{To cite this article :}

Shanmugasamy M, Rajeswar J (2012) Alpha toxin specific PCR for detection of toxigenic strains of Clostridium perfringens in poultry, Vet World, 5(6):365-368, doi: 10.5455/vetworld.2012.365-368

\section{Introduction}

Clostridium perfringens type A and to lesser extent type $\mathrm{C}$ causes necrotic enteritits (NE) in poultry. Normally, the number of $C$. perfringens in the intestine is low (about $10^{4} \mathrm{cfu} / \mathrm{g}$ of digesta). The disease occurs when high numbers of bacteria coincide with a damaged intestinal mucousa [1]. The disturbances in normal intestinal microfolora may cause rapid proliferation of C. perfringens, increasing bacterial numbers the range from $10^{7}$ to $10^{9}$ colony forming units $(\mathrm{cfu}) / \mathrm{g}$ of digesta resulting in toxin production [2]. So far, over 800 serotypes of $C$. perfringens are known and 17 different toxic fractions have been isolated [3]. The $C$. perfringens strains were classified into five toxinotypes (A, B, C, D and E) based on the production of four major toxins viz., alpha, beta, epsilon and iota [4]. C. perfringens type A strains produce the chromosomal encoded toxin, while $\mathrm{C}$. perfringens type $\mathrm{C}$ strains produce toxin together with toxin [5].

However, the chromosomal encoded alpha toxin is considered as the main virulence factor for $\mathrm{NE}$ in poultry because birds are about 200 times more susceptible to alpha toxin than to beta or epsilon toxin [6].

The alpha toxin has been implicated inseveral diseases including NE in chickens [7]. The toxin destruction of mucosal tissue manifests as macroscopic lesions that are usually seen in jejunum and ileum but can also appear in duodenum [8]. It is a potent toxin with haemolytic, lethal, dermonecrotic, vascular permeabilization and platelet aggregating properties [9] and it has direct effects on host metabolism 
including inhibition of neutrophil chemotaxis, vasoconstriction, haemolysis of erythrocytes and necrosis of other body cells and modulation of cell metabolism by activating the arachidonic acid cascade and protein kinase $\mathrm{C}$ [10]. The polymerase chain reaction assay (PCR) was used for detection of alpha toxigenic strains of C.perfringens [11-14].

In India, NE was first reported by Chakraborty, et.al., [15]. Now, the NE is emerged as a worldwide problem [16] and it is a common disease found in all poultry growing areas of the world.

Aim of the study was Isolation of clostridium perfirngens from necrotic enteritis cases in poultry and confirmation by alpha toxin specific PCR.

\section{Materials and Methods}

For isolation of the organism causing necrotic enteritis, thirty five birds suspected for NE were collected from poultry diagnostic and research centers of M/s. Suguna poultry farm, M/s. Venkateshwara Hatcheries Limited, Palladam, M/s. Pioneer Hatcheries, Namakkal. Apart from that, ten commercial farms in and around Namakkal and Udumalpet area from both broiler and layer farms, where, NE cases were reported.

For isolation of the organism causing necrotic enteritis, sterile saline (v/v) was added to the collected specimens consisting of intestinal contents and scrapings then heated at $80^{\circ} \mathrm{C}$ for $20 \mathrm{~min}$ in water bath. The processed Intestinal contents were inoculated into thioglycollate broth, Robertson cooked meat medium with brain heart infusion broth and sterile liquid paraffin was poured to make a layer over the medium. Inoculated medium was incubated at $37^{\circ} \mathrm{C}$ for $24 \mathrm{hr}$. The presence of $C$. perfringens in the inoculated sample is indicated by turbidity in both of the media. The positive cultures were streaked on to clostridial agar and perfringens agar with supplements. The plates were incubated in the anaerobic jar at $37^{\circ} \mathrm{C}$ for 48h.

The bacteria isolated anaerobically from NE specimens showed the characteristic colony types of $C$. perfringens, were gram stained and confirmed to be $C$. perfringens by standard biochemical tests as described by Barrow and Feltham [17].

I dentification of toxigenic strains by Polymerase Chain Reaction (PCR): To design the PCR, alpha toxin specific primers (CP - F- AGT CTA CGC TTG GGA TGG AA and CP - R- TTT CCT GGG TTG TCC ATT TC), which flanked 900 base pair DNA sequence, according to Baums et al., [18] were used.

To perform the PCR, 2 ul template DNA, prepared by the heat lysis method of Baums et al.,
2004, was added to a 50 ul reaction mixture with the following reagents $1.25 \mathrm{U}$ Taq DNA polymerase, 50 $\mathrm{mM}$ Pottassium chloride, $30 \mathrm{mM}$ Tris-Hcl, $1.5 \mathrm{mM}$ $\mathrm{Mg}^{2++}, 200 \mu \mathrm{M}$ of each dNTP and 50 picomoles of each primer. The thermocycling (incubations for $1 \mathrm{~min}$ at $95^{\circ} \mathrm{C}, 55^{\circ} \mathrm{C}$ and $72^{\circ} \mathrm{C}$ respectively was 35 times) was preceded by incubation for $2 \mathrm{~min} 30$ seconds at $95^{\circ} \mathrm{C}$. Six microlitre of the amplicons was separated on $1.5 \%$ agarose gel according to standard procedure.

\section{Results and Discussion}

Inoculation of processed intestinal contents in thioglycollate broth produced turbidity and saccharolytic reaction in Robertson cooked meat medium with brain heart infusion broth. Appreciable luxuriant growths on the clostridial agar were obtained on the initial streak from the culture. The selective streaking of these colonies on perfringens agar with supplements revealed rough and black colonies with sulphate reduction.

The isolates produced double zone haemolysis on sheep blood agar, stormy clot fermentation on milk medium and opalescence on egg yolk medium. The isolates were found negative for oxidase, catalase, liquefied gelatin, fermented glucose, maltose, lactose and sucrose except mannitol.

Based on the results obtained from the above said tests, and in consultation with Bergey's Manual of determinative bacteriology [19], the isolates were identified as $C$. perfringens. Thus twenty $\mathrm{Cl}$. perfringens isolates were obtained from the intestinal content of thirty five NE suspected broilers. Out of the twenty isolates, fourteen were isolated from commercial broilers of 2 to $6 \mathrm{wk}$ of age, six from commercial layers of 9 to $15 \mathrm{wk}$ of age. These findings correlate with the reports of detection of $C$. perfringens in 2-6 wk broiler chickens [20] and isolation of $C$. perfringens from 7 to $16 \mathrm{wk}$ commercial layer birds [21].

The primer combination used in this study was reliable and very specific in amplifying $900 \mathrm{bp}$ fragment of the alpha toxin gene- cpa of $C$. perfringens but not other genes $\mathrm{cpb}$, etx, iap, cpe and $\mathrm{cpb} 2$, encoding the $\beta, \varepsilon, 1$, entero and $\beta 2$ toxins of $C$. perfringens as proved by Baums, et.al., [18]. All the twenty isolates produced the predicted amplification size of $900 \mathrm{bp}$, with the gene coding for alpha toxin production (Fig .1) hence all the isolates are proved as the alpha toxin producing strains of C. perfringens. Similar to present study, Engstrom et al. [12] analysed 53 isolates of $C$. perfringens from NE affected poultry from different parts of Sweden by PCR for toxin typing. They reported that all the isolates were 


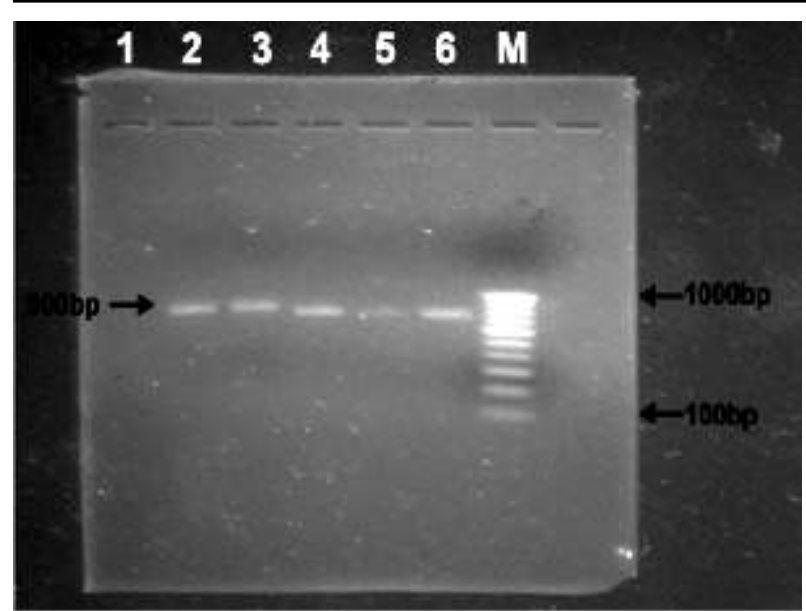

belonged to the toxin type A of C. perfringens. Several authors also noted that isolates from NE affected poultry were alpha toxin producing toxigenic strains of C. perfringens $[11,13,14]$.

Based on the study, we concluded that twenty isolates toxigenic strain of $C$. perfringens were isolated from necrotic enteritis cases in poultry farms in TamilNadu, India. PCR-based assay was used for the detection of $C$. perfringens. This method is rapid, sensitive, and specific. Although limited numbers of clinical samples were used in the present study, it has been shown that PCR could be a convenient tool for detecting $C$. perfringens infection because it requires minimal laboratory facilities and is relatively simple and inexpensive to perform.

\section{Acknowledgements}

Authors are thankful to Dean, VC\&RI, Namakkal for providing the facilities to carry out the work. We also thank officials $\mathrm{M} / \mathrm{s}$. Suguna poultry farm, Palladam, M/s. Venkateshwara Hatcheries Limited, Palladam and M/s. Pioneer Hatcheries, Namakkal for sending birds suspected for necrotic enteritis.

\section{Competing interests} interests.

The authors declare that they have no competing

\section{References}

1. Al-Sheikhly, F. and R. B. Truscott. (1977a) The interaction of Clostridium perfringens and its toxins in the production of necrotic enteritis of chickens. Avian Diseases, $21: 256-263$.

2. Kondo, F. (1988) In vitro lecithinase activity and sensitivity to 22 antimicrobial agents of Clostridium perfringens isolated from necrotic enteritis of broiler chickens. Research in Veterinary Science, 45: 337340 .

www.veterinaryworld.org
Figure-1. An agarose gel stained with ethidium bromide with PCR amplification products of C. perfringens isolates. Lane M: 100 bp ladder; Lanes 2 to 6: I solates
3. Hatheway, C.L. (1990) Toxigenic clostridia. Clinical Microbiology Review, 3: 66-98.

4. Songer, J. G. (1996) Clostridial enteric disease of domestic animals. Clinical Microbiology Review, 9 : 216-234.

5. Petit, L., M. Gibert, M. R. Popoff. (1999) Clostridium perfringens: toxinotype and genotype. Trends in Microbiology., 7 : 104 - 110. Cited in Immersal et al., 2004.

6. Dahiya, J.P., D.C. Wilkie, A.G. Van Kessel and M.D. Drew. (2006) Potential strategies for controlling necrotic enteritis in broiler chickens in post- antibiotic era. Anim. Feed Sci. Technol, 129:60-88.

7. Rood, J.I. (1998) Virulence genes of Clostridium perfringens. Annu.Rev. Microbiol. 52: 333-360.

8. Fukata, T., Y. Hadate, E. Baba, T. Uemura and A. Arakawa. (1988) Influence of Clostridium perfringens and its toxins in germ free chickens. Research in Veterinary Science, $44: 68-70$.

9. Titball, R.W. (1993) Bacterial phospholipases. Clinical Microbiology Review, 57: 468-476.

10. Titball, R.W., C.E. Naylor and A.K. Basak. 1999. The Clostridium perfringens alpha toxin. Anaerobe., 5: 51-64.

11. Schoepe, H., C. Pache, A. Neubauer, H. Potschka, T. Schlapp, L.H. Wieler and G. Baljer. (2001) Naturally occurring Clostridium perfringens non toxic alpha -toxin variant as a potential vaccine candidate against alpha-toxin- associated diseases. Infect. Immun., 69(11): 7194-7196.

12. Engstrom, B. E., C. Fermer, A. Saarinen, V. Baverud and A. Gunnarsson. (2003) Molecular typing of isolates of Clostridium perfringens from healthy and diseased poultry. Veterinary Microbiology, 94 : $225-235$.

13. Sheddy, S.A., A.B. Ingham, J.I. Rood and R.J. Moore. (2004) Highly conserved alpha-toxin sequences of avian isolates of Clostridium perfringens. Journal of Clinical Microbiology, 42(3) : 1345-1347.

14. Wilkie, D.C., A.G. Van Kessel, T.J. Dumonceaux, B. 
Laarveld and M.D. Drew. (2006) The effect of hen-egg antibodies on Clostridium perfringens colonization in the gastrointestinal tract of broiler chickens. Preventive Veterinary Medicine, 74(4): 279-292.

15. Chakraborty, G. C., D. Chakraborty, D. Bhattacharyya, S. Bhattacharyya, U.N. Koswami and H. M. Bhattacharyya. (1984) Necrotic enteritis in poultry in West Bengal. Indian Journal of Comparative Microbiology, Immunology and Infectious Diseases, 5: 54-57.

16. Immerseel, F. V., J. D. Buck, F. Pasmans, G. Huyghebaert, F. Haesebrouck and R. Ducatelle. (2004) Clostridium perfringens in poultry: an emerging threat for animal and public health. Review article. Avian pathology, 33(6): 537 - 549.

17. Barrow. G. I. and R. K. A. Feltham. (1993) Cowan and Steel's manual for the identification of medical bacteria, $3^{\text {rd }}$ Edn, Cambridge University Press,
Cambridge.

18. Baums, C.G., U. Schotte, G. Amtsberg and R. Goethe. (2004) Diagnostic multiplex PCR for toxin genotyping of Clostridium perfringens isolates. Veerinary Microbiology, 100: 11-16.

19. Holt,G.H., N.H. Krieg, P.H.A. Sneath, J.T Stanley and S.T. Williams. (1994) Bergey's manual of Determinative Bacteriology. $9^{\text {th }}$ edition. Williams and Wilkins publications. Baltimore.

20. Lovland. A. and M. Kaldhusdal. (2001) Severely impaired production performance in broiler flocks with high incidence of Clostridium perfringens associated hepatitis. Avian pathology, 30:73-81.

21. Wages, D. P. and K. Opengart. (2003) Necrotic Enteritis. In 'Diseases of Poultry', Y. M. Saif, H. J. Barnes, J. R. Glisson, A. M. Fadly, L. R. McDougald and D. E. Swayne (Eds.). $11^{\text {th }}$ edn. Ames: Iowa State Press. pp. $781-785$. 